\title{
(1) cranes \\ () \\ OPEN ACCESS \\ Therapeutic use of intermittent fasting and ketogenic diet as an alternative treatment for type 2 diabetes in a normal weight woman: a 14-month case study
}

\author{
Charlene Lichtash 이, ${ }^{1}$ Jason Fung, ${ }^{2}$ Katherine Connor Ostoich, ${ }^{3}$ Megan Ramos ${ }^{4}$
}

Department of Medicine, Cedars-Sinai Medical Center Beverly Hills, California, USA ${ }^{2}$ Department of Medicine, Scarborough Health Network, Scarborough, Ontario, Canada ${ }^{3}$ National University of Ireland Galway, Galway, Ireland ${ }^{4}$ Institute of Kidney Life Science Technologies, Scarborough, Ontario, Canada

Correspondence to Dr. Charlene Lichtash; charlene.lichtash@gmail.com

Accepted 12 June 2020
Check for updates

(c) BMJ Publishing Group Limited 2020. Re-use permitted under CC BY-NC. No commercial re-use. See rights and permissions. Published by BMJ.

To cite: Lichtash C, Fung J, Ostoich KC, et al. BMJ Case Rep 2020;13:e234223. doi:10.1136/bcr-2019234223

\section{SUMMARY}

This case demonstrates the effective and sustainable use of intermittent fasting (IF) and ketogenic diet (KD) in a normal weight patient with type 2 diabetes, who did not attain glycaemic control with a standard care approach. A 57-year-old woman with type 2 diabetes treated with metformin and strict adherence to a standard diabetic diet presented with a haemoglobin $\mathrm{A} 1 \mathrm{c}(\mathrm{HbA} 1 \mathrm{c})$ of $9.3 \%$. Within 4 months of transitioning to $K D$, combined with IF, she achieved glycaemic control off pharmacotherapy, with $\mathrm{HbA} 1 \mathrm{c}$ of 6.4 . IF regimens started as 24 hours three times per week, followed by 42 hours three times per week, then 42 hours two times per week and 16 hours once per week. A maintenance phase was then begun at 8 months; IF was reduced to 16 hours per day, with 24 hours three times per month, and metformin was restarted. At 14 months, $\mathrm{HbA} 1 \mathrm{c}$ reached $5.8 \%$, and body mass index was minimally changed.

\section{BACKGROUND}

Diabetes mellitus type 2 is a disease characterised by hyperglycaemia, varying levels of insulin resistance and impaired pancreatic beta-cell function. Both genetic and environmental factors contribute to the pathogenesis of type 2 diabetes. ${ }^{1}$ The growing epidemic of type 2 diabetes worldwide highlights the need for accessible preventative and therapeutic strategies. According to a global estimate by the WHO in 2014, an estimated 422 million adults were living with diabetes, with the prevalence of diabetes having doubled since $1980 .^{2}$ In 2012, diabetes was the eighth leading cause of death among both sexes and the fifth leading cause of death in women. ${ }^{2}$

Standard approaches to the treatment of type 2 diabetes incorporate lifestyle management, pharmacotherapy and occasionally bariatric surgery. ${ }^{3-5}$ The goal of treatment is euglycaemia and a reduction of the incidence of microvascular and macrovascular complications of type 2 diabetes. Medical nutrition therapy (MNT) is widely accepted as part of the standard of care in a diabetic patient. ${ }^{4}$ Guidelines cite several diets, including the Mediterranean diet, the Dietary Approaches to Stop Hypertension diet, vegetarian diet and low-carbohydrate diet, as effective in lowering haemoglobin A1c (HbA1c). ${ }^{4}$ However, there is no consensus on the ideal macronutrient composition of diet to achieve control or remission of type 2 diabetes. ${ }^{4}$ Ketogenic diets (KDs), which induce a state of nutritional ketosis (defined in the medical literature as a blood beta-hydroxybutyrate level of $0.5-3.0 \mathrm{mmol} / \mathrm{L}$ ), have demonstrated effective reduction in HbA1c and metabolic parameters in patients with type 2 diabetes; however, studies are limited in size and number. ${ }^{6-8}$

Remission in type 2 diabetes has been demonstrated in large trials studying caloric restriction, as well as bariatric surgery. ${ }^{9-11}$ While effective, bariatric surgery is limited by its accessibility, potential for complications and invasive nature. Caloric restriction is limited by long-term patient adherence. ${ }^{12}$ Caloric restriction results in compensatory changes in the hormonal regulators of body weight, effectively reducing energy expenditure and increasing hunger. ${ }^{12}$ These changes have been shown to persist for at least 12 months after implementing a calorierestricted diet, explaining the challenge in applying this approach to the treatment of type 2 diabetes. ${ }^{12}$

By contrast, intermittent fasting (IF) is emerging as a potentially sustainable strategy to achieve control or remission of type 2 diabetes. Fasting is the voluntary abstinence from food, and IF is an eating regimen by which all meals are consumed within a strictly defined window of time, followed by fasting. ${ }^{13}$ Some available studies on IF use variations of fasting that allow for the ingestion of fewer calories during this window, while others abstain from caloric intake altogether. ${ }^{13}$ Patterns and lengths of fasting also vary among studies. Studies on the therapeutic use of IF in type 2 diabetes are very limited. Herein, we present a case of woman with type 2 diabetes who successfully used a combination of IF and a low-carbohydrate KD to achieve glycaemic control.

While reduction of body weight is typically the goal of IF regimens, not all patients who suffer from type 2 diabetes are overweight. Many cases of type 2 diabetes improve or remit with weight loss, but the two goals are not the same. In this case, a change in dietary pattern effectively controlled type 2 diabetes, although the patient was not overweight and overall weight change was minimal.

\section{CASE PRESENTATION}

A 57-year-old woman with a 15-year history of type 2 diabetes had been managed for the majority of her illness with metformin and a standard diabetic diet. She had a remote history of gestational diabetes at age 20 and 34 years. At the time of her diagnosis 
with type 2 diabetes mellitus at age 42 years, her HbA1c was $7.1 \%$ and body mass index (BMI) was $21.9 \mathrm{~kg} / \mathrm{m}^{2}$, classified as normal weight. During the course of her illness, she had strictly adhered to a diet prescribed to her by a registered dietician and based on prior American Diabetes Association (ADA) guidelines. ${ }^{14}$ It had consisted of carbohydrates from fruits, vegetables, whole grains, legumes and low-fat dairy, as well as poultry, fish and nuts. She had strictly limited her intake of saturated fat, red meats, sweets, sugar-sweetened beverages and sodium. She had regularly eaten three meals per day with two snacks.

In June 2016, at age 54 years, her HbA1c had risen to $8.7 \%$ and BMI to $23.2 \mathrm{~kg} / \mathrm{m}^{2}$, while on metformin and her diabetic diet; glipizide was then added to her regimen. By February 2017, her HbA1c had only marginally improved to $8.3 \%$, but she experienced weight gain with a rise in her BMI to $24 \%$, a common side effect of sulfonylurea drugs. Pioglitazone was subsequently added to her regimen of metformin and glipizide, but she reported not taking it consistently due to episodes of hypoglycaemia and dizziness. In June 2017, her HbA1c was 7.8\%, and she was told to lower her dose of glipizide, continue metformin and to resume pioglitazone. In October 2017, her HbA1c had improved to $6.5 \%$; however, she reported frequent hypoglycaemia, dizziness and feeling unwell, and she discontinued her pioglitazone and glipizide on her own. In July 2018, her HbA1c had risen to $9.3 \%$ on a regimen of metformin and her diabetic diet.

\section{TREATMENT}

In July 2018, she began strictly following a KD, followed by the initiation of an IF regimen 2 weeks later. The KD, a lowcarbohydrate high-fat (LCHF) diet, consisted of the following macronutrient composition: $80 \%$ fat, $15 \%$ protein and $5 \%$ carbohydrates. The diet focused on eating natural, unprocessed fats containing a variety of monounsaturated and polyunsaturated sources. Protein was predominantly from pasture-raised chicken and eggs, grass-fed beef and wild-caught fish. Grains, starches, legumes and the majority of fruits were eliminated, with most of the carbohydrates in the diet consisting of leafy greens and raw or fermented vegetables. Total daily consumption was estimated to be $20-30 \mathrm{~g}$ of carbohydrates and 1500 calories. She reported eating to satiety, without strictly measuring calories.

IF was started at 24 hours three times per week on Monday, Wednesday and Friday. After 2 weeks, she increased the duration of fasting to 42 hours three times per week, which she continued for 4 months. Because of the significant improvement in blood glucose, and the lack of available data to guide the choice of a follow-up regimen, she then reduced her fasting to 42 hours on Mondays and Wednesdays, and 16 hours on Fridays for 4 months. In an effort to test the need for continued 42 hours fasts, a maintenance phase was then started, during which fasting was reduced to 16 hours per day and 24 hours three times per month for 6 months. Metformin $1000 \mathrm{mg}$ two times per day was reinitiated at the start of the maintenance phase. When not fasting, she ate two meals per day with no additional snacks between meals. On days she fasted 24 hours, she ate one meal per day. During fasts she drank water, plain tea or coffee and occasionally homemade bone broth.

\section{OUTCOME AND FOLLOW-UP}

Four weeks after initiating her dietary changes, the patient discontinued all medications, including metformin, an antihypertensive and a statin, while at the same time significantly improving glycaemic control. A timeline and summary of the patient's
Table 1 Timeline of patient treatment modality for type 2 diabetes and measured health parameters

\begin{tabular}{|c|c|c|c|c|}
\hline Date of visit & Treatment at time of visit & $\begin{array}{l}\text { HbA1C } \\
(\%)\end{array}$ & $\begin{array}{l}\text { Weight } \\
(\mathrm{kg})\end{array}$ & $\begin{array}{l}\text { BMI }(\mathrm{kg} / \\
\left.\mathrm{m}^{2}\right)\end{array}$ \\
\hline June 2016 & $\begin{array}{l}\text { Metformin } 1000 \mathrm{mg} \text { two times } \\
\text { per day }\end{array}$ & 8.7 & 57.8 & 23.2 \\
\hline February 2017 & $\begin{array}{l}\text { Metformin } 1000 \mathrm{mg} \text { two times } \\
\text { per day } \\
\text { Glipizide } 10 \mathrm{mg} \text { two times per day }\end{array}$ & 8.3 & 59.6 & 24.0 \\
\hline June 2017 & $\begin{array}{l}\text { Metformin } 1000 \mathrm{mg} \text { two times } \\
\text { per day } \\
\text { Glipizide } 10 \mathrm{mg} \text { two times per day } \\
\text { Pioglitazone } 15 \mathrm{mg} / \text { day (not taken } \\
\text { consistently due to side effects) }\end{array}$ & 7.8 & 58.2 & 23.5 \\
\hline October 2017 & $\begin{array}{l}\text { Metformin } 1000 \mathrm{mg} \text { two times } \\
\text { per day } \\
\text { Glipizide } 10 \mathrm{mg} / \mathrm{day}, 5 \mathrm{mg} \text { nightly } \\
\text { Pioglitazone } 30 \mathrm{mg} / \mathrm{day}\end{array}$ & 6.5 & 60.0 & 24.2 \\
\hline July 2018 & $\begin{array}{l}\text { Metformin } 1000 \mathrm{mg} \text { two times } \\
\text { per day }\end{array}$ & 9.3 & 55.3 & 22.3 \\
\hline $\begin{array}{l}\text { November } \\
2018\end{array}$ & $\begin{array}{l}\text { Ketogenic diet } \\
\text { Intermittent fasting }\end{array}$ & 6.4 & 51.7 & 20.9 \\
\hline $\begin{array}{l}\text { December } \\
2018\end{array}$ & $\begin{array}{l}\text { Ketogenic diet } \\
\text { Intermittent fasting }\end{array}$ & 6.1 & 52.6 & 21.2 \\
\hline January 2019 & $\begin{array}{l}\text { Ketogenic diet } \\
\text { Intermittent fasting }\end{array}$ & 6.5 & 53.0 & 21.4 \\
\hline February 2019 & $\begin{array}{l}\text { Ketogenic diet } \\
\text { Intermittent fasting }\end{array}$ & 6.1 & 52.1 & 21.0 \\
\hline March 2019 & $\begin{array}{l}\text { Ketogenic diet } \\
\text { Intermittent fasting }\end{array}$ & 6.4 & 54.9 & 22.1 \\
\hline $\begin{array}{l}\text { September } \\
2019\end{array}$ & $\begin{array}{l}\text { Ketogenic diet } \\
\text { Intermittent fasting } \\
\text { Metformin } 1000 \mathrm{mg} \text { two times } \\
\text { per day }\end{array}$ & 5.8 & 53.5 & 21.6 \\
\hline
\end{tabular}

BMI, body mass index; HbA1c, haemoglobin A1c.

diabetic medications with health parameters recorded at each visit are displayed in table 1 . HbA1c dropped by $2.9 \%$, from $9.3 \%$ to $6.4 \%$ during the first 4 months of dietary treatment, as depicted in figure 1. A few hypoglycemic episodes were noted only when initiating the IF regimen, but none subsequently. Her HbA1c at 8 months was $6.4 \%$, at which time, fasting insulin, postprandial insulin rise and $\mathrm{C}$ peptide were all at the lower end of normal range. At this point, when glycaemic control had been achieved, metformin was added. At 14 months, HbA1c was reduced to 5.8. The patient's weight and BMI were mildly reduced, as demonstrated in figure 2 , with her most recent weight and BMI being

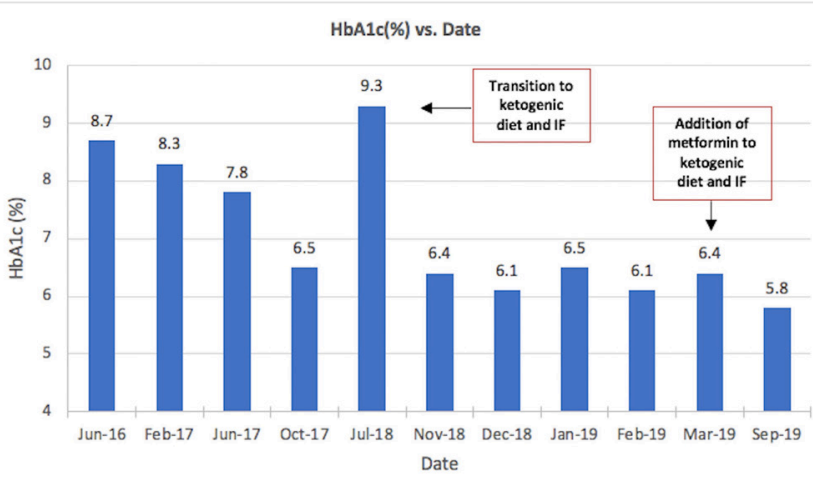

Figure 1 Glycosylated haemoglobin prior to and during treatment with intermittent fasting and ketogenic diet. $\mathrm{HbA1c}$, haemoglobin $\mathrm{A} 1 \mathrm{c}$. 


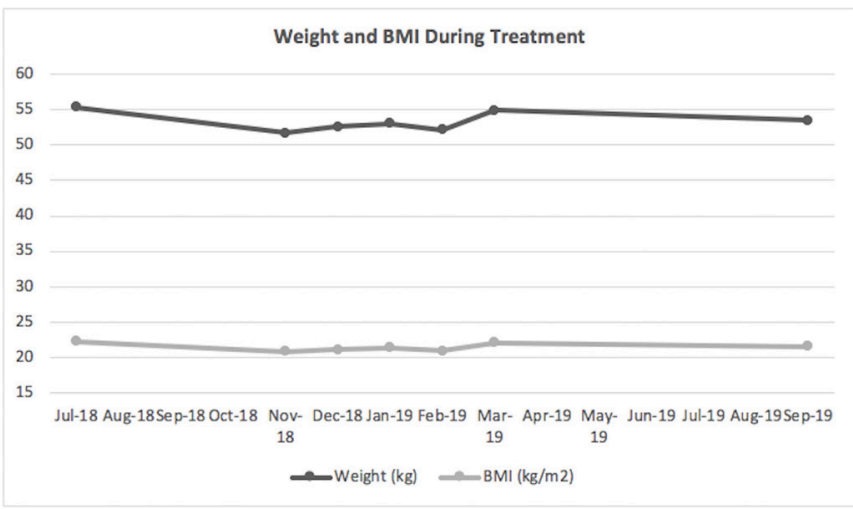

Figure 2 Weight and body mass index during treatment with intermittent fasting and ketogenic diet. BMI, body mass index.

$53.5 \mathrm{~kg}$ and $21.6 \mathrm{~kg} / \mathrm{m}^{2}$, respectively. When fasting, she recorded ketone levels at $0.5-1 \mathrm{mmol} / \mathrm{L}$ using a commercial blood ketone monitor, confirming nutritional ketosis. During the first 8 days after initiating $\mathrm{KD}$, the patient reported mild fatigue and headache. These self-limited symptoms are common when starting a KD and are often referred to colloquially as keto flu. Thereafter, she reported no difficulties in maintaining the diet and fasting regimen, and she noted an improvement in her energy level, exercise tolerance and quality of life. Despite tolerating the 42 hours fasting periods without difficulty, she reported greater satisfaction with her fasting regimen in the maintenance phase, citing a greater sense of normalcy when able to engage in daily meals. The patient currently continues with her KD and IF, which she plans to maintain indefinitely.

We present a case of a normal weight patient with uncontrolled type 2 diabetes despite adherence to oral hypoglycemic medications and standard dietary advice, who successfully managed her condition using a relatively novel lifestyle approach, combining IF with a KD. The therapeutic benefits of IF and KD in the management of type 2 diabetes are reported in the medical literature, but they have not been studied in large scale. Their use is guided predominately by an understanding of their proposed pathophysiologic mechanisms reported in animal data, and by outcomes reported in limited human data.

Studies on IF generally demonstrate its effectiveness in improving glycaemic control and other metabolic parameters, including reduction in visceral fat, blood pressure and markers of oxidative stress and inflammation. ${ }^{13}{ }^{15-20}$ The available human data for IF show marked benefit in pre-diabetes and type 2 diabetes. In a case report of three patients with long-standing type 2 diabetes each requiring at least 70 units of insulin per day, the implementation of 24 hours fasts either three times per week or on alternate days, combined with a recommended lowcarbohydrate diet resulted in the complete discontinuation of insulin in all three patients; reductions in $\mathrm{HbA} 1 \mathrm{c}, \mathrm{BMI}$ and waist circumference were also demonstrated. ${ }^{17}$ Moreover, the benefits of IF on insulin sensitivity extend beyond its influence on weight loss. A recent trial in men with pre-diabetes and overweight or obesity showed that 5 weeks of an IF regimen improved insulin sensitivity and pancreatic beta-cell responsiveness, independent of weight loss. ${ }^{20}$ Another study comparing caloric restriction to an IF regimen for weight loss showed a greater increase in insulin sensitivity when using an IF strategy. ${ }^{21}$ The findings in our case mirror those in the literature; IF was an effective and sustainable tool for achieving glycaemic control and reducing the need for pharmacotherapy in our patient, independent of weight loss.
Animal data propose a mechanistic understanding of the effects of IF on glycaemic control, providing hope that this treatment modality may slow or reverse the progression of type 2 diabetes. Mice fed a fasting-mimicking diet showed an increase in the proliferation and number of insulin-generating pancreatic beta cells in late-stage type 2 diabetes. ${ }^{22}$ Differentiated cells in the pancreas first decreased in number in the fasted state, and then pancreatic transitional cells and beta cells proliferated in the refed state. ${ }^{22}$ This study suggests that the therapeutic benefit of IF lies in the combined physiologic effects caused by both the fasted state, and by the recovery period during the feeding phase, to promote beta-cell repair. Another study in mice showed increased pancreatic beta-cell mass using IF. ${ }^{23}$ Glucose stimulated insulin secretion increased and beta-cell apoptosis decreased. ${ }^{23}$ Additionally, weight loss was not required for the benefits of IF on pancreatic beta-cell survival and function. ${ }^{23}$ The possibility that IF can promote pancreatic beta cells to regenerate and has the potential to revolutionise our treatment of type 2 diabetes, currently viewed as a chronic progressive disease. Further human studies are needed to help illuminate the potential role IF may have in slowing or reversing this disease.

The processes linking IF and benefits in insulin sensitivity are currently being studied to help with targeted pharmacologic therapy that can mimic effects of IF. One such area of ongoing research is in the sirtuin proteins, a family of enzymes with regulatory effects on glucose homeostasis, fat metabolism and life span regulated by both nutrient levels and calorie restriction. ${ }^{18} 19$ In particular, sirtuin-6 (SIRT6) is currently being studied as a potential therapeutic target for treating insulin resistance. ${ }^{24}$ SIRT6 in animal studies enhances insulin sensitivity and thereby decreases fasting blood glucose levels. ${ }^{24-26}$ Both shortterm fasting and long-term calorie restriction increase SIRT6 levels in animal data further highlighting the role IF may play in disease modification ${ }^{19}$

Carbohydrate restriction is considered an effective treatment of type 2 diabetes in standard MNT, as defined by the ADA and the European Association for the Study of Diabetes. ${ }^{4}$ This approach even predates the development of exogenous insulin treatment in 1921, and is based on the fact that carbohydrates are the macronutrient with the highest glycaemic and insulin indices. ${ }^{27}$ An increased carbohydrate intake worsens markers of insulin resistance, such as postprandial glucose and insulin levels. ${ }^{28}$ Several trials have demonstrated improvements in HbA1c and insulin sensitivity when implementing a low-carbohydrate diet. ${ }^{29}$ The benefits of dietary carbohydrate restriction on control of blood glucose do not necessarily require weight loss, and low-carbohydrate diets have been shown to be generally well tolerated. ${ }^{3031}$

While the benefits of low-carbohydrate diets in type 2 diabetes are well accepted, the role of KD in the management of type 2 diabetes is not widely accepted at the present time, partly due to limited long-term safety data. A KD is typically defined as a LCHF diet that induces a shift in energy source from glucose to fatty acids and fatty-acid-derived ketones. Achieving nutritional ketosis has been shown to result in diabetes remission and reversal in some cases. ${ }^{8}$ A non-randomised long-term study implementing KD found significant improvements in biomarkers, including HbA1c, weight, fasting glucose, fasting insulin, blood pressure, cholesterol profile, high sensitivity C-reactive protein and a reduced need for type 2 diabetic medication. ${ }^{6}$ By contrast, the control arm consisting of patients with type 2 diabetes receiving 'usual care' with counselling on lifestyle interventions by a registered dietitian showed no significant change in any of the biomarkers measured. ${ }^{6}$ 
However, in other disease states, both KDs and IF have a long history of safety. KD was first used in the 1920s in the treatment of epilepsy. ${ }^{32}$ During nearly a century of clinical use, there have been remarkably few health concerns. IF has been used even longer in the treatment of epilepsy, having been described by the ancient Greek physician Hippocrates more than 2400 years ago. ${ }^{33}$ Further, IF has been a traditional part of virtually every major religion in the world.

Our patient tolerated the KD well, with her only reported difficulty being the week-long initial period of adjustment, termed in popular media as keto flu and in the medical literature as keto induction. ${ }^{34}$ Common symptoms of keto flu include influenzalike symptoms, headache, fatigue, nausea, dizziness, gastrointestinal discomfort and decreased energy. ${ }^{34}$ The symptoms tend to peak within the first 7 days of initiating a KD and resolve within the first month. ${ }^{34}$ While data show that IF and the production of ketone bodies result in adaptive responses that influence health and longevity, further research on KDs is needed to help support their widespread use in the treatment of diabetes mellitus.

IF and a low-carbohydrate diet, such as a KD, appear to be particularly effective when used in combination. These two dietary interventions address different but complementary parts of the total diet. A KD specifies which foods should or should not be eaten (what to eat), but does not give guidance on the timing of meals (when to eat). IF provides guidance on the meal timing but not meal composition. Together they provide a complete dietary solution that each lacks on its own.

The time to achieving glycaemic control in type 2 diabetes with this combined approach varies, and further studies are needed to define the determining factors, such as degree of insulin resistance and pancreatic beta-cell reserve. Our patient achieved glycaemic control within 4 months of combining KD and IF. Another study found that in three patients with insulin-dependent diabetes, implementation of IF and a low-carbohydrate diet resulted in discontinuation of insulin between 5 and 18 days of initiating treatment. ${ }^{17}$ For maintenance of glycaemic control, the duration and degree of IF and carbohydrate restriction must also be tailored to the individual patient. As demonstrated in our case, once glycaemic control was achieved the lengths of fasts were able to be reduced, without compromising glycaemic control. Further studies should help identify patient characteristics that predict ideal fasting lengths and carbohydrate limits in the management of type 2 diabetes.

The available data on KD and IF is encouraging, and our case report and review of the literature highlights the need for more extensive research on these two treatment modalities in the

\section{Learning points}

- The use of intermittent fasting (IF) and a ketogenic diet (KD) is an effective and sustainable alternative to a standard care approach in the treatment of type 2 diabetes.

- IF and a KD can be used in a patient with type 2 diabetes who is normal weight. Glycaemic control can be achieved without resulting in significant weight loss.

- The use of this dietary strategy minimises or eliminates the need for pharmacotherapy, and it may be superior to a standard care approach to type 2 diabetes.

- We demonstrate good adherence to a strategy of IF and a $K D$ in a patient who could not tolerate the adverse effects of additional oral hypoglycemic medications when under a standard care approach. treatment of type 2 diabetes. With the alarming rise in incidence of type 2 diabetes worldwide, the need for cost-effective and widely available strategies to manage this disease is growing. The need for pharmacotherapy and invasive bariatric surgery can be effectively lowered through the use of our approach. Further, as shown in animal and preliminary human data, the strategies we discussed in our study have the potential to modify the course of type 2 diabetes, which has long been understood as a chronic progressive disease. If validated in large-scale randomised studies, the current data on both IF and KD have the potential to revolutionise our understanding of the pathophysiology of type 2 diabetes and profoundly impact the standard approach to treatment of this disease.

\section{Twitter Jason Fung @drjasonfung}

Contributors $\mathrm{CL}$ compiled patient history, medical records and data, performed literature review and developed introduction and discussion and finalised the remaining sections of the report. $\mathrm{KCO}$ synthesised data and drafted the case history, treatment and results section of the case report. JF and MR edited the case report through several revisions.

Funding The authors have not declared a specific grant for this research from any funding agency in the public, commercial or not-for-profit sectors.

Competing interests None declared.

Patient consent for publication Obtained.

Provenance and peer review Not commissioned; externally peer reviewed.

Open access This is an open access article distributed in accordance with the Creative Commons Attribution Non Commercial (CC BY-NC 4.0) license, which permits others to distribute, remix, adapt, build upon this work non-commercially, and license their derivative works on different terms, provided the original work is properly cited and the use is non-commercial. See: http://creativecommons.org/ licenses/by-nc/4.0/.

\section{ORCID iD}

Charlene Lichtash http://orcid.org/0000-0003-3166-1373

\section{REFERENCES}

1 Schulz LO, Bennett PH, Ravussin E, et al. Effects of traditional and Western environments on prevalence of type 2 diabetes in Pima Indians in Mexico and the U.S. Diabetes Care 2006:29:1866-71.

2 Roglic G. Global report on diabetes. Geneva, Switzerland: World Health Organization, 2016: 86.

3 Qaseem A, Barry MJ, Humphrey LL, et al. Oral pharmacologic treatment of type 2 diabetes mellitus: a clinical practice guideline update from the American College of physicians. Ann Intern Med 2017;166:279-90.

4 Davies MJ, D'Alessio DA, Fradkin J, et al. Management of hyperglycemia in type 2 diabetes, 2018. A consensus report by the American diabetes association (ADA) and the European association for the study of diabetes (EASD). Diabetes Care 2018;41:2669-701

5 American Diabetes Association. Pharmacologic Approaches to Glycemic Treatment: Standards of Medical Care in Diabetes-2019. Diabetes Care 2019:42:590-102.

6 Hallberg SJ, McKenzie AL, Williams PT, et al. Effectiveness and Safety of a Novel Care Model for the Management of Type 2 Diabetes at 1 Year: An Open-Label, NonRandomized, Controlled Study. Diabetes Ther 2018;9:583-612.

7 Dashti HM, Mathew TC, Hussein T, et al. Long-Term effects of a ketogenic diet in obese patients. Exp Clin Cardiol 2004;9:200-5.

8 Athinarayanan SJ, Adams RN, Hallberg SJ, et al. Long-Term effects of a novel continuous remote care intervention including nutritional ketosis for the management of type 2 diabetes: a 2-year Non-randomized clinical trial. Front Endocrinol 2019:10:348.

9 Sjöström L, Peltonen M, Jacobson P, et al. Association of bariatric surgery with long-term remission of type 2 diabetes and with microvascular and macrovascular complications. JAMA 2014;311:2297-304.

10 Mingrone G, Panunzi S, De Gaetano A, et al. Bariatric surgery versus conventional medical therapy for type 2 diabetes. N Engl J Med 2012;366:1577-85.

11 Lean ME, Leslie WS, Barnes AC, et al. Primary care-led weight management for remission of type 2 diabetes (direct): an open-label, cluster-randomised trial. Lancet 2018;391:541-51.

12 Sumithran $P$, Prendergast LA, Delbridge E, et al. Long-Term persistence of hormonal adaptations to weight loss. N Engl J Med 2011;365:1597-604.

13 Zubrzycki A, Cierpka-Kmiec K, Kmiec Z, et al. The role of low-calorie diets and intermittent fasting in the treatment of obesity and type-2 diabetes. J Physiol Pharmacol 2018;69:1-3 
14 American Diabetes Association, Bantle JP, Wylie-Rosett J, et al. Nutrition recommendations and interventions for diabetes: a position statement of the American diabetes association. Diabetes Care 2008;31 Suppl 1:S61-78.

15 de Cabo R, Mattson MP. Effects of intermittent fasting on health, aging, and disease. N Engl J Med 2019;381:2541-51.

16 Ding H, Zheng S, Garcia-Ruiz D, et al. Fasting induces a subcutaneous-to-visceral fat switch mediated by microRNA-149-3p and suppression of PRDM16. Nat Commun 2016:7:11533.

17 Furmli S, Elmasry R, Ramos M, et al. Therapeutic use of intermittent fasting for people with type 2 diabetes as an alternative to insulin. BMJ Case Rep 201810.1136/bcr2017-221854. [Epub ahead of print: 09 Oct 2018].

18 Kanfi Y, Peshti V, Gozlan YM, et al. Regulation of SIRT1 protein levels by nutrient availability. FEBS Lett 2008;582:2417-23.

19 Kanfi Y, Shalman R, Peshti V, et al. Regulation of SIRT6 protein levels by nutrient availability. FEBS Lett 2008:582:543-8.

20 Sutton EF, Beyl R, Early KS, et al. Early Time-Restricted feeding improves insulin sensitivity, blood pressure, and oxidative stress even without weight loss in men with prediabetes. Cell Metab 2018;27:1212-21.

21 Harvie MN, Pegington M, Mattson MP, et al. The effects of intermittent or continuous energy restriction on weight loss and metabolic disease risk markers: a randomized trial in young overweight women. Int J Obes 2011;35:714-27.

22 Cheng C-W, Villani V, Buono R, et al. Fasting-Mimicking diet promotes Ngn3-Driven $\beta$-cell regeneration to reverse diabetes. Cell 2017;168:775-88.

23 Liu H, Javaheri A, Godar RJ, et al. Intermittent fasting preserves beta-cell mass in obesityinduced diabetes via the autophagy-lysosome pathway. Autophagy 2017;13:1952-68.

24 Tang W, Fan Y. Sirt6 as a potential target for treating insulin resistance. Life SCi 2019;231:116558.
25 Qin K, Zhang N, Zhang Z, et al. SIRT6-mediated transcriptional suppression of Txnip is critical for pancreatic beta cell function and survival in mice. Diabetologia 2018;61:906-18

26 Kanfi Y, Peshti V, Gil R, et al. Sirt6 protects against pathological damage caused by diet-induced obesity. Aging Cell 2010;9:162-73

27 Westman EC, Yancy WS, Humphreys M. Dietary treatment of diabetes mellitus in the pre-insulin era (1914-1922). Perspect Biol Med 2006;49:77-83.

28 Kodama S, Saito K, Tanaka S, et al. Influence of fat and carbohydrate proportions on the metabolic profile in patients with type 2 diabetes: a meta-analysis. Diabetes Care 2009:32:959-65.

29 Wheeler ML, Dunbar SA, Jaacks LM, et al. Macronutrients, food groups, and eating patterns in the management of diabetes: a systematic review of the literature, 2010 Diabetes Care 2012;35:434-45.

30 Nickols-Richardson SM, Coleman MD, Volpe JJ, et al. Perceived hunger is lower and weight loss is greater in overweight premenopausal women consuming a low-carbohydrate/high-protein vs high-carbohydrate/low-fat diet. J Am Diet Assoc 2005;105:1433-7.

31 Gannon MC, Nuttall FQ. Control of blood glucose in type 2 diabetes without weight loss by modification of diet composition. Nutr Metab 2006:3:16.

32 D'Andrea Meira I, Romão TT, Pires do Prado HJ, et al. Ketogenic diet and epilepsy: what we know so far. Front Neurosci 2019:13:5.

33 Hippocrates. On the sacred disease 400 BCE. Available: http://classics.mit.edu/ Hippocrates/sacred.htm

34 Bostock ECS, Kirkby KC, Taylor BV, et al. Consumer Reports of "Keto Flu" Associated With the Ketogenic Diet. Front Nutr 2020;7:20.

Copyright 2020 BMJ Publishing Group. All rights reserved. For permission to reuse any of this content visit https://www.bmj.com/company/products-services/rights-and-licensing/permissions/ BMJ Case Report Fellows may re-use this article for personal use and teaching without any further permission.

Become a Fellow of BMJ Case Reports today and you can:

- Submit as many cases as you like

Enjoy fast sympathetic peer review and rapid publication of accepted articles

- Access all the published articles

Re-use any of the published material for personal use and teaching without further permission

Customer Service

If you have any further queries about your subscription, please contact our customer services team on +44 (0) 2071111105 or via email at support@bmj.com.

Visit casereports.bmj.com for more articles like this and to become a Fellow 